\title{
CONSUMERS' DECISION-MAKING IN ONLINE GROCERY SHOPPING: THE IMPACT OF SERVICES OFFERED AND DELIVERY CONDITIONS
}

\author{
Radka Bauerová ${ }^{1}$ \\ 'Department of Business Economics and Management, Faculty of Business Administration, Silesian University in \\ Karviná, Univerzitní náměstní 1934/3, 73340 Karviná, Czech Republic
}

To cite this article: BAUEROVÁ RADKA. 2018. Consumers' Decision-Making in Online Grocery Shopping: the Impact of Services Offered and Delivery Conditions. Acta Universitatis Agriculturae et Silviculturae Mendelianae Brunensis, 66(6): 1239-1247.

To link to this article: https://doi.org/10.11118/actaun201866051239

\begin{abstract}
The growing consumer interest in buying food online has caused that online grocery shopping (OGS) is the current most evolving e-commerce category. Therefore, focus on the factors influencing e-consumer's decision-making is an important key to tailor optimal marketing strategy. OGS is specific due to the food aspects (quality, freshness and durability) as well as to the offered services and delivery conditions of the online purchase process. The aim of the paper is to extend external factors of online consumer decision process and examine the influence of offered services and delivery conditions toward consumer's decision-making in online grocery shopping. The paper focuses primarily on the choice of the type of service and the determination of delivery conditions that have a positive impact on the customer's decision-making. The empirical analysis was conducted on a sample of Czech online grocery buyers involving 536 respondents interviewed online. The results show the high customer sensitivity in delivery time and charge, while the impact of the minimum required order on the consumer's intention to shop grocery online is not so decisive. The results suggest the Delivery Passes is the consumer most requested service and could play a role in building loyalty.
\end{abstract}

Keywords: online grocery shopping, e-commerce, decision-making process, consumer behaviour, marketing strategy, services, delivery conditions

\section{INTRODUCTION}

The rising share of Internet users changed the way, how individuals seeking and sharing information, have a contact with friends and acquaintances, telephoning, reading news, looking for a job, spending leisure time and buying goods or services. Despite the increasing interest surrounding online consumer behaviour in the last years, there is a paucity of research on consumer's decision-making process in online grocery shopping.

The consumer's decision-making process entails the steps consumers go through to make decisions between marketplace alternatives (product choice, brand choice, store choice or brand item options, paying possibilities, and even whether or not to make a purchase at all) (Lantos, 2015). The decision process has five stages (problem recognition, search, alternative evaluation, purchase and outcomes), which are affected by external factors (Engel $e t$ al., 1986). Darley et al. (2010) include individual characteristics, social influences, situational and economic factors and online environment (website quality, website interface, website satisfaction and 
website experience) into external factors of online consumer decision process.

Online environment offer some specific attributes influenced consumer's decision-making process. The most frequently mentioned attributes of online grocery shopping are time-saving (Morganosky et al., 2000; Anesbury, 2015) and saving of effort during the purchase process (Seiders et al., 2007; Sreya and Raveendran, 2017). These two attributes belong to the perceived convenience factor, the most frequently mentioned benefits of online shopping. Perceived convenience is a construct that reflects consumers' perceived time and effort in purchasing (Seiders et al., 2007). These two attributes apply to online consumer's decision-making in general for all categories of services and products. However, the online grocery shopping area is specific due to the products itself. Many grocery items, such as fruits and vegetables, belong to the see, touch or smell category, making it impossible to explore the products quality before online purchase (Citrin et al., 2003). While some e-tailers can guarantee a superior products freshness, quality, products meet one's expectation and receiving the products in time, the perceived risk of failure to meet these requirements significantly affects online customers (Huang and Oppewal, 2006). Therefore, a decision-maki ng process in buying grocery online can be different in some ways (in external factors) from the in-store shopping and online shopping in general.

Most of the previous research into online grocery shopping (OGS) has focused on identifying consumer attitudes toward online grocery stores (Morganosky et al., 2000; Ramus and Nielsen, 2005; Kacen et al., 2013; Anesbury, 2015). Other scientists have often focused on examining factors affecting consumer's OGS acceptance (Kurnia and Chien, 2003), the influence of situational factors (Robinson et al., 2007; Hand et al., 2009), and motivations (hedonic and utilitarian) for online grocery shopping behaviour (Childers et al., 2001).

The previous research in OGS has focused less on delivery conditions and services offer, despite that these external factors relate to the perceived convenience and can influence the decision-making process. The time-saving attribute has a relationship with delivery conditions depending on the delivery time in OGS. Effort-saving attribute has a relationship with services offered to facilitate the buying process of food. Therefore, the deeper research in this area is important for better understanding how mentioned external factors can influence a customer's decision-making in OGS.

This paper focuses on extending external factors of online consumer decision process for online grocery area. The service offer and delivery conditions are proposed factors with the expected influence on the decision-making process of customers purchasing grocery online. This paper also deals with the exploration of what kind of services offered choose and how to set delivery conditions to influence consumers' decision-making in online grocery shopping positively. The author answers the following questions in undertaking this research:

- RQ1: What impact does the services and delivery conditions on consumers' decision-making in online grocery shopping?

- RQ2: What are the optimal delivery conditions for online grocery customer's to influence decision-making positive?

The aim of the paper is to extend external factors of online consumer decision process and examine the influence of offered services and delivery conditions toward consumer's decision-making in online grocery shopping. The literature review analyses the perception of online grocery shopping worldwide with a focus on the Czech Republic as a place of research and existing online grocery shopping articles related to the delivery conditions and services offer. The following part introduces the chosen research method to find out the links between offered services and delivery conditions and consumer's decision-making in OGS. The fourth part of this paper describes and comments on the results provided. Tables are also used for better visualisation of the results. The last part of the paper summarises the proven connections between mentioned external factors and consumer's decision-making in relation to demographic factors.

\section{The perception of online grocery shopping}

At the beginning of the online purchases search only a few countries (Turkey 20\%, United Kingdom 17\%) has a share of online grocery higher than 10 percent (Eurostat, 2004). The perception of online grocery shopping (OGS) has changed in the last quarter of a century. OGS is the most evolving category on the online market in 2017. There is a growing share of European people shopping grocery online in comparison with 2016 (Eurostat, 2017). The growing share of individuals buying grocery online is also evident in the USA, where $19 \%$ of consumers purchased grocery online in 2016, while $31 \%$ of consumers are estimated in 2017 (Statista, 2017).

Looking at the EU Member States, more than 3 out of 10 internet users in the Netherlands (37\%), Estonia (35\%), in the United Kingdom (34\%), Slovenia (31\%) and Lithuania (30\%) shopped grocery online during the previous year. No or slight decline in online grocery shopping is only visible in Croatia (0\%) and Romania (-1\%). (Eurostat, 2017)

The research in this paper is oriented on the Czech consumers. If we focus on the development of Czech online grocery share, we can see a moderate and gradual the growth of individuals buying grocery online until 2015 (see Fig. 2). The slight increase share of online grocery customers in 2012 can be linked to the situation when Tesco began offering online food via iTesco service (Justice, 2013). Tesco is only one hybrid organization (retail and e-tail) 


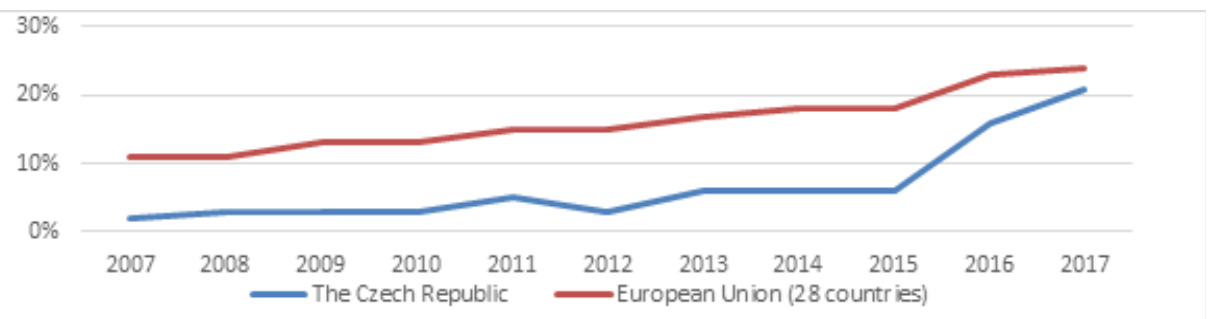

1: The comparison of Czech and European Union development of online grocery shopping Source: author's illustration from the Eurostat online database.

on the Czech online grocery market. This market is specific to a large number of e-tail marketers, for example, the most known are Rohlík.cz, Koloniál. cz, Košík.cz and Myfood.cz. The Koloniál.cz and Košík.cz companies entered the market in 2015 (Justice, 2014), which brought not only the growth of the segment competition but also can cause the significant increase of consumer interest as are visible in Fig. 2.

The proportion of consumers purchasing grocery online is in the Czech Republic (21\%) just below the EU average (24\%) in 2017, which is visible in Fig. 2. The strong competition in the market led to set more favourable delivery conditions for purchase grocery online. The situation also caused better services offered to distinguish the company from other competitors.

\section{Delivery conditions and services offered in OGS}

OGS is specific due to the food aspects (quality, freshness and durability), which can be reflected in delivery conditions and services offered as attributes of the online purchase process.

The majority of e-shoppers in the EU had not experienced any problems when ordering or buying online, but $17 \%$ of e-shoppers had a problem with delay of delivery (Eurostat, 2017). If we focus on deliveries of grocery in general, this factor affects consumers shopping channel preference and consumers behaviour. Huang and Oppewal (2006) found that consumers are at least as concerned about the travel time to the store as they are about delivery fees. Fifteen minutes difference in travel time to the grocery store had a greater impact on the relative preference to shop online then the delivery fee of $£ 5$ in their research. The delivery fee is dependent on receiving concepts alternatives (pick-up by the customer, shared reception boxes, own reception box in the household and attended reception) and delivery cost is different (over 40 percent) when using different receiving concepts (Kämäräinen et al., 2001).

Delivery time is another important attribute in consumer's decision-making. Previous research shows that orders placed between 2 and 5 days in advance of delivery time, for each additional day in advance of delivery an order is completed, the percent of "want" (e.g., frozen pizza, ice cream, cookies) groceries decreases and the percent of "should" (e.g., eggs, milk, vegetables) groceries increases (Milkman et al., 2010). It can be analogically assumed that consumers expected less delivery time with higher order value because higher order value can indicate a presence of "want" items and "should" items in the online shopping basket.

Online environment offers a new way, how to create, develop and manage services offered to online grocery customers. Managers can by systematically examining customers' demand chains and value offerings that correspond to these chains, the online grocery shop can come up with new, meaningful and flexible services that increase the value of online grocery shopping perceived by the customers (Småros et al., 2000). Based on the literature review the following hypotheses are formulated:

- Hl: Services offered (included Click and Collect, financial services and Delivery Passes) form one of the important factors in consumer decision-making toward online grocery shopping. - H2: Delivery conditions (included delivery fee, minimum delivery order and delivery time) form one of the important factors in consumer decision-making toward online grocery shopping.

\section{MATERIALS AND METHODS}

This paper focus on services offered and delivery conditions as an external factors extension of online consumer decision-making process in the online grocery area. The online questionnaires with Likert scales were employed to find out the respondent's level of agreement or disagreement (attitudes) with statements. The range of Likert scale captures the intensity of their feelings for a given question (Likert, 1932). Likert scales have a seven-point scale in this research from I definitely agree item to I definitely disagree item.

\section{Sample}

The primary data were collected in cooperation with IPSOS research agency in the Czech Republic. The primary data were collected at the end of 2017. The panel is certified by SIMAR authority and has several control mechanisms to ensure data quality. A total of 1050 respondents' answers was obtained. Despite the mentioned mechanisms for quality control, the data set was examined for missing data, outliers and data distribution (Hair et al., 2017). There was no missing data found. Outliers were analysed in case of age by SPSS box plot. The box 
I: Sample distribution by age

\begin{tabular}{lcc}
\multicolumn{1}{l}{ Age category } & Count & Percent \\
16-24 year & 62 & 11.57 \\
25-34 year & 123 & 24.07 \\
\hline 35-44 year & 123 & 24.07 \\
$\mathbf{4 5 - 5 4}$ year & 107 & 19.96 \\
$\mathbf{5 5 - 6 5}$ year & 109 & 20.34 \\
Source: own calculation & & \\
& & \\
II: Sample distribution by salary & Count & Percent \\
\hline \multicolumn{1}{c}{ Respondents' salary } & 268 & 50 \\
\hline Up to 583 EUR & 212 & 39.6 \\
584-1,166 EUR & 45 & 8.4 \\
1,667-1,943 EUR & 11 & 2 \\
More than 1,943 EUR & &
\end{tabular}

Source: own calculation

III: Items used in the questionnaire.

\begin{tabular}{l|cc}
\hline \multicolumn{1}{c}{ Construct } & Question & Code \\
\hline $\begin{array}{l}\text { Services } \\
\text { offered }\end{array}$ & If there is a possibility to order the grocery online and pick it up in a shop \\
(Click and Collect service), I would buy it online. & S1 \\
& If a merchant offered extra services to buy grocery, such as financial services, \\
I would buy it online. & If a merchant offered a Delivery Passes service \\
$\begin{array}{l}\text { Delivery } \\
\text { conditions }\end{array}$ & I do not care about the delivery times of online groceries that are longer than 24 hours. & D1 \\
& I am willing to pay more than 2.7 EUR as a delivery fee. & D2 \\
\hline
\end{tabular}

Source: own formulation

plot did not show any outlier. Histograms and Q-Q Plots did not show any major normality problems.

Next analysis of data focused on buying frequency. In respect to search regular customers due to the subject of the study (for example Delivery Passes is primarily a service for regular customers), some cases (buying frequency less than several times a year) were eliminated from the following analysis. The total of 514 respondents was excluded from the following analysis because services and delivery conditions examined in this research are set up on a long relationship with customers and repetitive purchases. This procedure left 536 applicable answers from respondents to examine. The percentage of gender distribution in the sample is $47.9 \%$ in case of females and $52.1 \%$ in the case of males. Mean for the age group was 40.8 years $(S D=13.1)$ ranging from 17 to 65 years. The following table specifies the age group categories in detail.

The grand proportion of respondents was from of the largest regions, such as Prague (16.4\%), Central Bohemia (13.6\%), South Moravia (12.9\%), Moravia-Silesia (9.3\%) to mention just a few. Next
Tab. shows the distribution of respondents by salary calculated according to the Czech National rate determined by the Czech Central Bank (rate used in this research was $1 \mathrm{EUR}=25.725 \mathrm{CZK}$, date $=23$. 8. 2018)

\section{Hypotheses testing techniques selected}

The statistical analysis in this paper involved three distinct stages. In the first stage, a multivariate statistical technique-factor analysis will be used to find a new set of variables (services offered and delivery conditions) using the IBM SPSS software. Factor analysis is concerned with the identification of structure within a set of observed variables (Stewart, 1981).

A principal component analysis was performed, followed by a Direct Oblimin rotation of all factors with eigenvalues greater than one and a fixed number of factors to extract was two. Direct Oblimin rotation was chosen when looking at Component Correlation Matrix, where a significant correlation between factors is .454. In this exploratory study, a variable was considered a part of a factor if it had a factor loading of .5 or greater on one. 
KMO and Bartlett's test of sphericity was used to check the suitability of data for factor analysis. The examined data are suitability for factor analysis by rejected a null hypothesis (Sig. $=0.0$ ). Kaiser-Meyer-olkin Measure of sampling adequacy is 0.816 , which indicate the sampling is adequate (Cerny and Kaiser, 1977).

The statements formulated for questionnaire are shown in Tab. III. These statements were formulated for testing if there is an identification of structure.

In the second stage, will examine correlations between variables in new factors and buying frequency and the total amount of order to find any relationships between mention variables.

In the last stage, the Frequencies analysis will be used on the basic ordinal data to find services and delivery conditions preferred by customers.

\section{RESULTS}

An exploratory factor analysis confirmed two new factors in the consumer decision-making process toward online grocery shopping. The SPSS extracted two components explained $64.2 \%$ of the variance (the Eigenvalue $>1$ ). Tab. 4 reports the six items with their respective factor loadings. The first hypothesis was confirmed; therefore, services offered included Click and Collect (.909), financial services (.645) and
Delivery Passes (.670) form one of the important factors in consumer decision-making toward online grocery shopping. The second hypothesis was also confirmed, therefore delivery conditions included a delivery fee (.771), minimum delivery order (.762) and delivery time (.851) form one of the important factors in consumer decision-making toward online grocery shopping.

The second test examined variables in newly defined factors (services offered and delivery conditions) and consumers' buying frequency to find if there is a correlation indicating the relationship between these factors. These correlations are listed in Tab. VI. Some guidance on how to describe correlations used an eleven-step scale from the perfect positive correlation $(+1.00)$ to perfect negative correlation (-1.00) (Fitz-Gibbon and Morris, 1987). By using an eleven-step scale to interpret all coefficients, S1- Click and Collect service has a statistically significant (.004) probably no correlation with buying frequency. However, there is a statistically significant weak correlation between S2-Financial service, S3-Delivery Passes and buying frequency. This can indicate that in general, an impact of services offered on buying frequency is a positive. If we focus on Dl-delivery time and D3-minimum order value, there is a statistically significant (.000) weak correlation

IV: Factor analysis of the initial 6-item involvement scale.

\begin{tabular}{lccc}
\hline \multicolumn{1}{c}{ Group } & Variable & Factor 1 & Factor 2 \\
\hline \multirow{3}{*}{ Services offered } & S1 & & .909 \\
& S2 & .617 & $\underline{.645^{*}}$ \\
Delivery conditions & S3 & .670 & \\
& D1 & .771 & \\
\hline
\end{tabular}

*Factor loadings that are underlined were used as the basis for interpreting the factors.

Source: own calculation

V: Correlations between variables in factors, buying frequency and the total amount of order.

\begin{tabular}{|c|c|c|c|c|}
\hline Factor & Variable & & Buying frequency & The total amount of order \\
\hline \multirow{6}{*}{ Service offered } & \multirow{2}{*}{ S1 } & Pearson Correlation & $.088^{* *}$ & -.054 \\
\hline & & Sig. (2-tailed) & .004 & .079 \\
\hline & \multirow{2}{*}{ S2 } & Pearson Correlation & $.125^{* *}$ & $-.094^{* *}$ \\
\hline & & Sig. (2-tailed) & .000 & .002 \\
\hline & \multirow{2}{*}{ S3 } & Pearson Correlation & $.184^{* *}$ & $-.318^{* *}$ \\
\hline & & Sig. (2-tailed) & .000 & .000 \\
\hline \multirow{6}{*}{ Delivery conditions } & \multirow{2}{*}{ D1 } & Pearson Correlation & $.165^{* *}$ & $-.268^{* *}$ \\
\hline & & Sig. (2-tailed) & .000 & .000 \\
\hline & \multirow{2}{*}{ D2 } & Pearson Correlation & $.061^{*}$ & .058 \\
\hline & & Sig. (2-tailed) & .049 & .061 \\
\hline & \multirow{2}{*}{ D3 } & Pearson Correlation & $.175^{* *}$ & $-.256^{* *}$ \\
\hline & & Sig. (2-tailed) & .000 & .000 \\
\hline
\end{tabular}

*Correlation is significant at the 0.01 level. ${ }^{* *}$ Correlation is significant at the 0.05 level.

Source: own calculation 
with buying frequency. The variable D2-delivery fee has probably no correlation with buying frequency. The test results indicate that in general delivery conditions can play a role in consumers' buying frequency.

The test also examines a correlation between the variables in the factors and the total amount of consumer's order. The correlation between Click and Collect service (S1) and the total amount of order was not significant (.079) as well as the correlation between Delivery fee (D2) and the total amount of order (.061). The financial services (S2) is a statistically significant variable; however, there is probably no correlation between the total amount of order. There is only one variable in services offered factor statistically significant (.000) with a weak negative correlation with the total amount of order. This variable is a Delivery Passes (S3). If we focus on variables in delivery conditions, there is two variable (delivery time and minimum delivery order) statistically significant (.000) with a weak negative correlation with the total amount of order. The delivery fee variable is not a statistically significant (.061).

The following paragraphs will examine the results of the Frequencies analysis used to find services and delivery conditions preferred by customers. The results of the analysis are shown in Fig. 2 and 3.

The preferred services offered are examined in Fig. 2. The Delivery Passes service is the most popular among customers and $70.9 \%$ of them would buy the grocery online if the merchant will offer this service. Click and Collect service is also perceived as very positive and $55.5 \%$ customers would buy grocery online if this service is offered. If we focus on the financial services, there is a different situation in perceiving this service. The difference between customers who rated financial services positively and negatively due to buying grocery online is only $13.4 \%$ and one-third of respondent answered neutrally. Therefore, the financial services have the least impact of research variables on consumers' decision-making process in online grocery shopping.

The next Fig. shows a customers' preferred delivery conditions. The delivery time, delivery fee and a minimum delivery order variables are specified in the following paragraph.

It was found that more than half (54.8\%) customers do not care about the delivery times of online groceries if the delivery time is longer than 24 hours, but $70 \%$ of customers would be discouraged from buying grocery online in case of delivery time is more than three days. Almost $50 \%$ of customers are willing to pay more than 2 EUR as a delivery fee, but not more than 2.7 EUR. If a merchant requires a minimum order value, more than half (54.9\%) customers agree with 19.8 EUR, which correlate with the total amount of order.

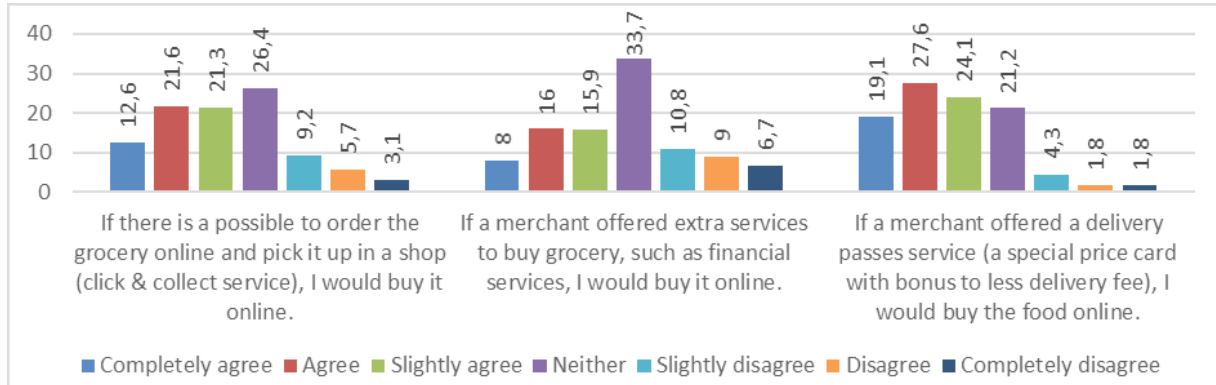

2: The graphics visualization of customers' preference for services offered Source: own calculation

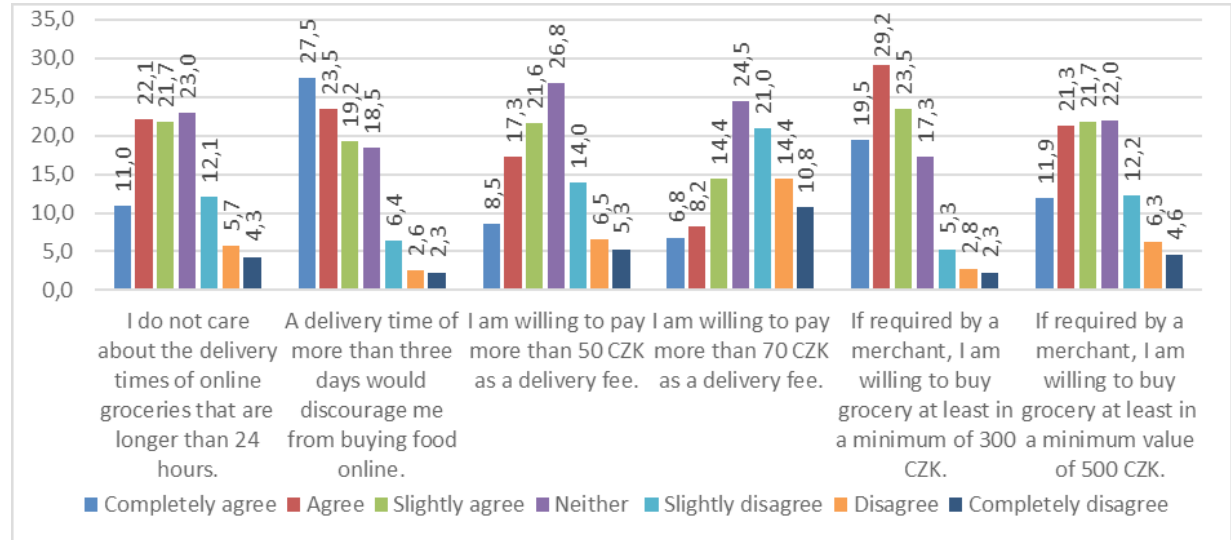

3: The graphics visualization of customers' preference for delivery conditions Source: own calculation 


\section{Limitations}

The major limitations of this study relate to the method used, the acquisition of the data examined and their relevance.

Exploratory factor analysis was the method used in this research. This method has its limits, like any method. The most frequently major limitations of factor analytic techniques are followed. The first is the quantum of techniques for performing exploratory factor analyses, controversy exists over which technique is the best. The second problem is the subjective aspects of factor analysis in deciding how many factors to extract, which technique should be used to rotate the factor axes or which factor loadings are significant. The last of three major exploratory factor analysis problem is that problem of reliability is real (Hair et al., 2017).

The way of the acquisition of the data examined can be seen as another problem due to data collected form. Research panel was chosen for collecting the data, but in this way, the motivation to earn money may override the interest in research study resulting in careless responses. This study measured only perceptions and intentions, not the actual decision making. Thus, the results are not as relevant as it would be in the experimental research.

\section{DISCUSSION}

The proved factor analysis confirmed services offered and delivery conditions as new factors in consumer decision-making toward online grocery shopping. Therefore these factors can be added to external factors of online grocery shopping (include individual characteristics, social influences, situational and economic factors and online environment) as Darley et al. (2010) stated for online shopping. Each factor was analysed by three variables. It can be said that the services offered and delivery conditions factors have an impact on consumers' decision-making process. These two factors explained $64.2 \%$ of the variance in the online grocery shopping decision-making process. This paper can be useful for scientists oriented on technology acceptance model (TAM) in online grocery shopping as a base to choose external variables in structural equation modelling. There is a possibility of relationships between services offered or delivery conditions with perceived usefulness or perceived ease of use in TAM. Therefore these two factors can be set as indirect predictors of behavioural intention in TAM oriented on online grocery shopping.

The Correlations between variables in factors, buying frequency and the total amount of order was examined to find any relationship. The analysis found that financial service and Delivery Passes weakly positive correlate with buying frequency. This can be explained by a reality that when deploying these services, customers can increase their purchasing frequency as they can afford to buy more often (financial services), and the same delivery charge (Delivery Passes) applies to more frequent purchases. The weakly correlate with buying frequency was found also in delivery time and minimum order value as variables of delivery conditions factor. The positive correlation with delivery time can be linked to the availability of delivery terms when more available delivery terms can cause orders that are more frequent. The correlation analysis between variables in factors and the total amount of consumer's order found a statistically significant weak negative correlation with Delivery Passes, delivery time and minimum delivery order. The correlation with Delivery Passes can be linked to a situation when customers save for a delivery fee, which caused they can buy more goods for the money saved and thus increase the total amount of order. Delivery time may affect the total amount of consumers' order because if the delivery slot is not the closest delivery time the number of online shoppers can decrease. The minimum delivery order can then be directly proportional to the total amount of order if customers want to buy less.

The last analysis focused on finding services and delivery conditions preferred by customers. By the analysis was found the Delivery Passes service is the most popular among customers and $70.9 \%$ of them would buy the grocery online if the merchant will offer this service. Whereas this service is limited to a certain period, i.e. validity of a delivery card, therefore this card can increase a customers' loyalty. Click and Collect service is the second most popular service for customers and $55.5 \%$ of them would buy the grocery online if the service is offered. The optimal delivery time is deliveries no longer than 3 days for $70 \%$ of online grocery customers. Almost $50 \%$ of customers are willing to pay more than 2 EUR as a delivery fee, but not more than 2.7 EUR; therefore, the optimal delivery fee can be between these values. More than half customers agreed with 19.8 EUR as a minimum order value, but $72.2 \%$ preferred 11.9 EUR. The managerial implication is in set up optimal services and delivery conditions offered to influence a consumers' decision-making process in a positive way. The optimal services and delivery conditions offer of online grocery shops should be set up as follows: Delivery Passes as a base of services offered, 2 EUR delivery fee, 11.9 EUR as a minimum order value and delivery time no longer than 3 days to positively influence a consumers' decision-making for $70 \%$ of potential customers. 


\section{CONLUSION}

Online grocery shopping is the current most evolving e-commerce category worldwide. With the growth of individuals purchasing grocery online, there is also a growing need for scientists and managers to recognize and understand the factors that affect consumers' deci-sion-making. This paper examined services offered and delivery conditions as possible factors influencing online consumers when purchasing grocery. It was found, these factors can be added to external factors influencing consumers' decision-making when shopping grocery online, by exploratory factor analysis proved. The second test examined variables in services offered and delivery conditions factors, consumers' buying frequency and the total amount of order to find if there is a correlation indicating the relationship between these factors. The test results indicate that in general delivery conditions can play a role in consumers' buying fre-quency, an impact of services offered on buying frequency is a positive and the correlations between variables in factors and the total amount of consumer 's order are statistically signifi-cant weak negative (deeper discussed in the discussion section). The last analysis was oriented on consumers' preferences. The optimal services and delivery conditions offered to influence a consumers' decision-making process in a positive way was found by the Frequencies analy-sis. The efforts of marketers should, therefore, focus primarily on the optimal setting to positively influence a consumers' decision-making for $70 \%$ of potential customers includes Delivery Passes as a base of services offered, 2 EUR delivery fee, 11.9 EUR as a minimum order value and delivery time no longer than 3 days. These results can be used mainly in the area of online retailing, marketing communications and customer relationship man-agement for improving the quality of service provided.

Acknowledgements

This research was financially supported by the Student grant competition project SGS/7/2017: "Acceptance of technology from the perspective of marketing tools."

\section{REFERENCES}

ANESBURY, Z., NENYCZ-THIEL, M., DAWES, J. and KENNEDY, R. 2015. How do shoppers behave online? An observational study of online grocery shopping. Journal of Consumer Behaviour 15: 1-11.

CERNY, C. A. and KAISER, H. F. 1977. A study of a measure of sampling adequacy for factor-analytic correlation matrices. Multivariate Behavioral Research, 12(1): 43-47.

CHILDERS, T. L., CARR, C. L., PECK, J. and CARSON, S. 2001. Hedonic and utilitarian motivations for online retail shopping behavior. Journal of Retailing, 77(4): 511-535.

CITRIN, A. V., STEM, D., SPANGENBERG, E. R. and CLARCK, M. J. 2003. Consumer need for tactile input: an internet retailing challenge". Journal of Business Research, 56(11): 915-922.

DARLEY, W. K., BLANKSON, C. and LUETHGE, D. J. 2010. Toward an integrated framework for online consumer behavior and decision making process: A review. Psychology $\sigma$ Marketing, 2(27): 94-116.

ENGEL, J. F., BLACKWELL, R. D. and MINIARD, P.W. 1986. Consumer behavior. $5^{\text {th }}$ Edition. Hinsdale, IL: Dryden.

EUROSTAT. 2004. Internet purchases by individuals. [Online]. Available at: http://appsso.eurostat.ec.europa.eu/ nui/submitViewTableAction.do [Accessed: 2018, January 8].

EUROSTAT. 2017. Digitaleconomy G society in the EU:A Arowsethrough our online world in figures [Online]. Available at: http://ec.europa.eu/eurostat/cache/infographs/ict/bloc-2a.html [Accessed: 2018, January 8].

HAIR, J., HULT, G. T. M., RINGLE, C. M. and SARSTEDT, M. 2017. A Primer on Partial Least Squares Structural Equation Modeling. $2^{\text {nd }}$ Edition. Los Angeles: Sage.

HAND, C., RILEY, F. D., HARRIS, P., SINGH, J. and RETTIE, R. 2009. Online grocery shopping: the influence of situational factors. European Journal of Marketing, 43(9): 1205-1219.

HUANG, Y. and OPPEWAL, H. 2006. Why consumers hesitate to shop online: An experimental choice analysis of grocery shopping and the role of delivery fees. International Journal of Retail and Distribution Management, 35(4/5): 334-353.

JUSTICE. 2013. Tesco stores ČR, a.s. report. Veřejný rejstrík a Sbírka listin. [Online]. Available at: https:// or.justice.cz/ias/ui/vypis-sl-firma?subjektId=1325 [Accessed: 2018, January 19].

JUSTICE. 2014. Koloniál.cz and košík.cz foundation agreement. Veřejný rejstř́lk a Sbirka listin. [Online]. Available at: https://or.justice.cz/ias/ui/rejstrik-firma.vysledky?subjektId=867236\&typ=PLATNY [Accessed: 2018, January 19].

KACEN, J. J., HESS, J. D. and CHIANG, W. K. 2013. Bricks or Clicks? Consumer Attitudes toward Traditional Stores and Online Stores. Global Economics and Management Review, 18(1): 12-21.

KÄMÄRÄINEN, V., SARANEN, J. and HOLMSTRÖM, J. 2001. The reception box impact on home delivery efficiency in the e-grocery business. International Journal of Physical Distribution $\sigma$ Logistics Management, $31(6): 414-426$. 
KURNIA, S., CHIEN, J. A. W. and WESTARP, F. 2003 "The Acceptance of Online Grocery Shopping". In: Proceedings of 16th Bled eCommerce Conference eTransformation. University of Maribor, 9-11 June. Slovenia: Faculty of Organizational Sciences, University of Maribor, pp. 219-233.

LANTOS, G. P. 2015. Consumer Behavior in Action: Real-life Applications for Marketing Managers. New York: Routledge.

LIKERT, R., 1932. A technique for the measurement of attitudes. Archives of psychology, 140(33): 1-55.

MILKMAN, K. L., ROGERS, T. and BAZERMAN, M. H. 2010. I'll have the ice cream soon and the vegetables later: A study of online grocery purchases and order lead time. Marketing Letters, 21(1): 17-35.

MORGANOSKY,M.A. and BRENDA,J. C. 2000. Consumer response to online grocery shopping. International Journal of Retail $\sigma$ Distribution Management, 28(1): 17-26.

RAMUS, K. and NIELSEN, N. A. 2005. Online grocery retailing: what do consumers think? Internet Research, 15(3): 335-352.

ROBINSON, H., DALL'OLMO R., RETTIE, R. and ROLLS-WILLSON, G., 2007. The role of situational variables in online grocery shopping in the UK. The Marketing Review, 7(1): 89-106.

SEIDERS, K., VOSS, G. B., GODFREY, A. L. and GREWAL D. 2007. "SERVCON: Development and Validation of a Multidimensional Service Convenience Scale," Journal of the Academy of Marketing Science, 35(1): 144-56.

SMÅROS, J., HOLMSTRÖM, J. and KÄMÄRÄINEN, V. 2000. New Service Opportunities in the E-grocery Business. The International Journal of Logistics Management, 11(1): 61-74.

SREYA, R. and RAVEENDRAN, P.T. 2017. Effect of shopping orientations on attitude towards online shopping - a multiple regression approach. Management Insight, 12(2): 1-7.

STATISTA. 2017. Share of consumers likely to buy groceries online in the United States from 2015 to 2017. Statista: The Statistic Portal. [Online]. Available at: https://www.statista.com/statistics/754815/onlinegrocery-consumer-share/ [Accessed: 2018, January 8].

STEWART, D. W. 1981. The Application and Misapplication of Factor Analysis in Marketing Research. Journal of Marketing Research, 18(1): 51-62. 